\title{
Um framework para tratamento do léxico afetivo a partir de textos disponibilizados em um ambiente virtual de aprendizagem
}

\author{
Magalí T. Longhi, Gustavo Simonato, Patricia A. Behar, Magda Bercht \\ Programa de Pós-Graduação em Informática na Educação \\ Universidade Federal do Rio Grande do Sul (UFRGS) \\ Caixa Postal 5071 - 90.041-970 - Porto Alegre - RS - Brasil \\ mlonghi@cesup.ufrgs.br, fagundess13@gmail.com, pbehar@terra.com.br, \\ bercht@inf.ufrgs.br
}

\begin{abstract}
Resumo. Os ambientes virtuais de ensino e aprendizagem considerados "sensíveis afetivamente" devem ser capazes de identificar aspectos afetivos dos participantes em interação. A maioria dos sistemas utiliza as tecnologias de computação afetiva para captar emoções a partir de informações fisiológica, comportamental, gestual e modulação da fala. Técnicas para análise de subjetividade vêm sendo desenvolvidas para classificar conteúdo emocional em textos. Este artigo apresenta o framework AWM (Affect Word Minig) para mineração de palavras com conotação afetiva e examina os resultados preliminares sobre o reconhecimento da afetividade em textos registrados no Fórum do ambiente virtual de aprendizagem (AVA) ROODA.
\end{abstract}

Palavras-chave. Mineração de subjetividade, afetividade, ambientes virtuais de aprendizagem

\begin{abstract}
Virtual teaching and learning environments are considered "emotionally sensitive" when they are able to identify affective aspects in their users. Most of this systems use affective computing technologies to capture the emotions from physiological, behavioral, gestures and modulation of speech. Subjectivity analysis is used to classify the emotional content in texts. This article presents the framework AWM (Affect Word Minig) used to the affective recognition in Forum messages of the virtual learning environment (VLE) ROODA.
\end{abstract}

Keywords. Subjective mining, affectivity, virtual learning environment

\section{Introdução}

As emoções e seu impacto sobre o aprendizado e o rendimento escolar e acadêmico é tema de estudo em áreas multidisciplinares, principalmente na pedagogia e psicologia. Os estudos destacam a função da dimensão afetiva no processo de ensinar e aprender, sem jamais subestimar os outros aspectos (cognitivos e sociais) envolvidos na aprendizagem. Assim, parte-se do pressuposto de que a educação a distância, tanto quanto a presencial, devem considerar os aspectos afetivos. Questiona-se como as ferramentas tecnológicas podem proporcionar ambientes mais sensíveis ao novo paradigma que se apresenta à Educação: introdução de tecnologias de informação e comunicação e a inferência da afetividade por meio delas. 
A palavra emoção, do latim emovere, significa "colocar em movimento". Etimologicamente, o significado da palavra "emoção" tem a mesma origem que a da palavra "motor": aquilo que "põe em movimento" ou "serve para movimentar algo". Tal relação é vista na obra de Piaget (2005) quando o autor utiliza a metáfora do automóvel e a gasolina para destacar o quanto o aspecto afetivo é fator energético para o desenvolvimento intelectual. Essa energia pode influenciar o funcionamento da inteligência, sem jamais modificar suas estruturas (como a gasolina aciona o motor, mas não o modifica). Dessa forma, Piaget reconheceu, sobretudo no artigo A Relação da Afetividade com a Inteligência no Desenvolvimento Mental da Criança de 1962 (Piaget 2005), que a afetividade é o agente motivador da atividade cognitiva.

Muitos pesquisadores (Ekman, 1999; Damásio, 1996) classificam as emoções em primárias e secundárias. As emoções primárias foram altamente discutidas por Ekman (1999) no que tange às diferenças culturais. O autor identificou seis emoções básicas (ou utilitárias): medo, raiva, tristeza, alegria, surpresa e aversão, que servem para garantir a sobrevivência humana e são encontradas em qualquer cultura, independente da raça, língua ou religião.

As emoções secundárias ou sociais são adquiridas ou aprendidas a partir das primárias, conforme se vivencia uma série de situações cotidianas e suas consequências. No ambiente de aprendizagem, um aluno pode se deparar com sentimentos negativos (decepções, frustrações, sentimentos de culpa e vergonha, ciúmes, inveja, humilhação, etc.) ou positivos (entusiasmo, interesse, orgulho, etc.). A valência das emoções (positiva ou negativa) depende dos eventos disparadores (internos ou externos) e das crenças e desejos do aluno para atingir os resultados.

Quase sempre, o emprego do termo “emoção” está relacionado às emoções primárias ou secundárias. As emoções primárias acontecem espontânea e repentinamente, em alta intensidade. Já as secundárias, permanecem mais tempo e as reações são bem marcadas. Contudo, Damásio (1996) apresenta a noção das emoções de segundo plano. Essas emoções são de caráter ondulatório e difuso, originadas a partir das anteriores. Acompanham o sujeito por um período bem maior que as secundárias, muitas vezes observadas no comportamento não-verbal do sujeito. Tanto as emoções primárias quanto secundárias afetam o processo de aprendizagem. Porém, as de segundo plano, são as que mais influenciam na tomada de decisão.

Neste estudo utiliza-se o conceito de emoções de segundo plano. Aqui serão tratadas por estados de ânimo. Estado de ânimo é definido como um episódio difuso, de baixa intensidade, de longa duração, sem causa aparente (Scherer 2005). Pode ser caracterizado tanto como um processo cognitivo de valência positiva (estímulos atrativos) ou negativa (estímulos repulsivos), quanto como um conjunto estruturado de crenças de possíveis estados afetivos futuros (prazer ou dor).

Ao mesmo tempo, pesquisas na área da Computação Afetiva vêm sendo direcionadas para detectar o estado afetivo e a atenção do aluno. Desta forma, aplicações educacionais "sensíveis social/afetivamente" revelam-se capazes de exibir os conteúdos de acordo com a receptividade do aluno no momento da aprendizagem. Apresentam resultados mais promissores do que investigações por meio de perfis ou preferências informados e/ou estilos de aprendizagem previamente reconhecidos. 
Muitos trabalhos estão direcionados na captura da afetividade através das informações fisiológicas, comportamental e gestual nos ambientes de aprendizagem (Kapoor e Picard, 2005; Jaques et all., 2009; Kapur et all., 2005). Para isso são feitas análises de expressões faciais, do rastreamento dos olhos, da condutividade da pele, da pressão e posicionamento do corpo na cadeira e do modo como o aluno interage com o ambiente. Pesquisas também vêm sendo desenvolvidas para capturar as emoções nas modulações da fala (Scherer, 1995; Grandjean et al., 2006) e conteúdo emocional na escrita (Gill et all., 2008, Galati et all., 2008; Alm et all., 2005). O tratamento computacional da subjetividade em texto é feito através de técnicas conhecidas por Mineração de Opinião (Opinion Mining), Análise de Sentimento (Sentiment Analysis), Análise da Subjetividade (Subjectivity Analysis) ou Análise de Julgamento (Appraisal Extraction).

Este artigo apresenta os resultados preliminares obtidos na aplicação do framework AWM (Affect Word Minig), baseado na tecnologia Análise de Julgamento, em mensagens do Fórum do AVA ROODA. O AWM classifica as palavras que possuam conotação afetiva nos grupos de emoções que determinam o estado de ânimo do aluno. Assim, na próxima seção, faz-se uma breve descrição do léxico afetivo da língua portuguesa. Na seção 3, apresenta-se o AVA ROODA e a funcionalidade de comunicação de estudo. Na seção 4, apresenta-se o modelo de comunicação afetiva adotado. A seção 5 trata do framework AWM e a seção 6, a pesquisa e os resultados encontrados. Finalmente, são feitas algumas considerações a propósito do trabalho desenvolvido.

\section{Léxico afetivo da língua portuguesa}

Neste artigo, utiliza-se o conceito tradicional de léxico como sendo o acervo de palavras que compõe a língua. Isto é, o vocabulário de uma língua (Trask, 2008). O sistema léxico da língua reflete as circunstâncias históricas vivenciadas pela sociedade (Azeredo, 2008). No indivíduo, o léxico forma o vocabulário de expressão oral e de escrita utilizado no processo comunicativo adquirido com a sua experiência sóciocultural acumulada através do tempo.

A palavra, isolada do contexto, quase não tem significância. Contudo, existe nela "um núcleo significativo mais ou menos estável e constante" (Garcia, 1982) que serve de base à construção de substantivos, adjetivos, verbos e advérbios. Este núcleo é conhecido por lexema ou semantema. Assim, o lexema pode ser visto como uma palavra ou parte da palavra que serve de base ao sentido por ela expresso: denotativo ou conotativo.

A denotação tem sentido referencial, isto é, corresponde aos traços semânticos mais constantes e estáveis (não subjetivo) de caráter específico ou genérico (Garcia, 1982). Os lexemas: carro, casa, chapéu, planta (nos significados de árvore, desenho arquitetônico e sola do pé), etc. são palavras denotativas. Já a conotação, de caráter virtual e de constituição subjetiva, tem sentido afetivo. Através do sentido conotativo, a palavra expressa as atitudes do indivíduo, tais como: apreço, desprezo ou repulsa; tranquilidade ou pânico; distanciamento ou aproximação; valorização ou depreciação (Azeredo, 2008). Uma palavra pode ter significado denotativo e conotativo dependente das associações, vivências e experiências do indivíduo. Por exemplo, a palavra cão tem 
sentido denotativo quando designa o animal; mas é conotativo (e metafórico) quando expressa desprezo ou servidão.

A tonalidade afetiva (ou valor afetivo) de uma palavra é realçada por recursos inerentes ao próprio significado ou da forma particular como é empregada. A tonalidade afetiva será percebida pelo contexto, pela inflexão da voz na expressão oral ou por recursos gráficos, como aspas, grifos, letras maiúsculas, cores, emoticons (ícones criados a partir de uma sequência de pontuação, por exemplo, :- e :-) ) e outros na expressão escrita. Dessa forma, a tonalidade afetiva pode ser encontrada em palavras de significado afetivo, que exprimem julgamento, como elemento de avaliação contendo ou não afixos, palavras evocativas (estrangeirismos, indigenismos, arcaísmos, regionalismos e gírias) e linguagem figurada (Martins, 2008).

Neste artigo, são consideradas as palavras de significado afetivo cujo lexema exprime sentimentos (exteriorização psíquica) e desejos (apelo ou vontade) que ao receber vogal temática, desinência ou afixo atualiza-o como substantivo, adjetivo ou verbo. Os conjuntos: 1) amor, amar, amoroso; 2) triste, tristeza, tristonho, entristecer; 3) medo, medroso, amedrontar; 4) etc. são exemplos de palavras com significado afetivo. Também são consideradas as palavras que exprimem julgamento, representadas por adjetivos que conferem qualidades positivas ou negativas (bom/mau, valente/medroso, verdadeiro/mentiroso, esperto/tolo, etc.).

\section{ROODA: ambiente virtual de aprendizagem}

Um ambiente virtual de aprendizagem (AVA) pode ser definido como um espaço virtual formado pelos sujeitos participantes (aluno, professor e tutor) e materiais de ensino e de aprendizagem contidos nele; pelas interações que ocorrem e relações que se formam; e pelas formas de comunicação disponibilizadas para as trocas de informações. Este espaço virtual é muitas vezes conhecido por plataforma (Behar, 2009).

O ROODA (Rede coOperativa De Aprendizagem) ${ }^{1}$ é um AVA desenvolvido com base em princípios construtivistas tendo implícita a concepção epistemológica interacionista (Piaget, 1973). O principal objetivo é a mudança de paradigma educacional sob a premissa da interação como princípio fundamental da aprendizagem e do processo de cooperação dos usuários em AVA.

As funcionalidades de comunicação síncrona (Bate-papo, A2) e assíncrona (Fórum, Diário de Bordo, Lista de Discussão, Contatos) do AVA ROODA possibilitam encontros virtuais e espaços de convivência. Esses espaços sustentam o movimento de negociações, discussões e coordenações, e servem de subsídios para observar os fenômenos afetivos subjacentes.

A funcionalidade Fórum é um tipo de comunicação assíncrona na qual a interação dos participantes acontece de forma não simultânea. Tal funcionalidade permite a discussão e troca de ideias em diversos encontros. Não é necessário que todos estejam conectados ao ambiente ao mesmo tempo, mas todos têm acesso às contribuições do grupo exigindo um posicionamento do participante a partir das outras opiniões, provocando um diálogo.

\footnotetext{
${ }^{1}$ http://www.ead.ufrgs.br/rooda
} 
As trocas de opiniões, as negociações, as discussões e as reflexões, podem emergir, explicita ou implicitamente, a afetividade presente no sujeito através dos textos disponibilizados nessa funcionalidade, verificadas e assinaladas através da mineração subjetiva de textos.

\section{Modelo de comunicação afetiva}

O modelo de comunicação afetiva proposto neste trabalho refere-se à representação do reconhecimento dos estados de ânimo expressos em mensagens registradas na funcionalidade Fórum do AVA ROODA. Os textos são submetidos à mineração subjetiva e para cada lexema afetivo encontrado, é verificado em que posição da Roda dos Estados Afetivos - REA (Longhi et al., 2009a) o lexema se encontra.

A REA (Figura 2), definida a partir de extenso estudo teórico e justificativas empíricas realizadas por Scherer (2005) e Tran (2004), foi adotada para normalizar a pesquisa. O uso da REA se justifica especialmente por representar as emoções num espaço contínuo, em vez de discreto como em outras teorias. É dividida em quadrantes e subquadrantes.

Os quadrantes caracterizam os estados de ânimo representativos no processo de aprendizagem: satisfeito (quadrante I), insatisfeito (quandrante II), desanimado (quadrante III) e animado (quadrante IV). Cada um dos estados de ânimo engloba as famílias afetivas classificadas a partir dos tipos de emoções consideradas logrativas (satisfação), antagônicas (insatisfação), resignativas (desânimo) e condutivas (ânimo).

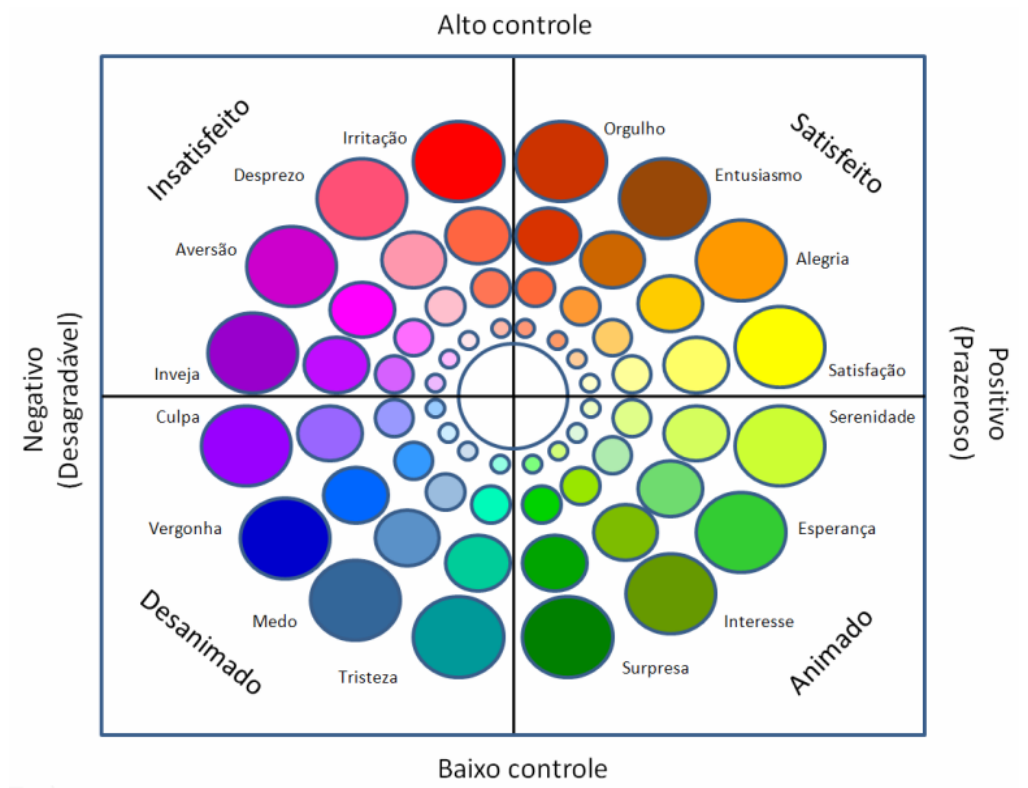

Figura 2. Espaço de representação dos estados de ânimo (Tran, 2004)

Os subquadrantes são determinados por grupos de emoções que definem uma família de termos afetivos. Por exemplo, a família afetiva representada pela alegria agrupa os termos (ser/estar/ter/sentir-se): alegre, amoroso, bem-humorado, caloroso, carinhoso, contente, deleite, ditoso, divertido, encantado, feliz, iluminado, lisonjeado, logrado, merecedor, premiado, privilegiado, qualificado, querido, simpático, sincero, valente, valorizado, vivo, entre outros. Os termos foram agrupados segundo a similaridade de significados. 


\section{Framework de análise dos léxicos afetivos}

O framework AWM (Affect Word Minig) foi desenvolvido no NUTED (Núcleo de Tecnologia Digital Aplicada à Educação) da UFRGS e está em fase de ajustes para implementação no AVA ROODA. O AWM classifica as palavras de conotação afetiva de um texto nos quadrantes da REA. É composto pelos módulos (Figura 3): recuperação de textos disponibilizados nas funcionalidades de comunicação do AVA (neste artigo, destaca-se o uso do Fórum); preprocessamento dos textos para a identificação de palavras afetivas; indexação para classificação conforme o modelo de comunicação afetiva; inferência dos estados de ânimo; e; visualização dos resultados obtidos. A descrição de cada módulo pode ser encontrado em Longhi et alli (2009b).

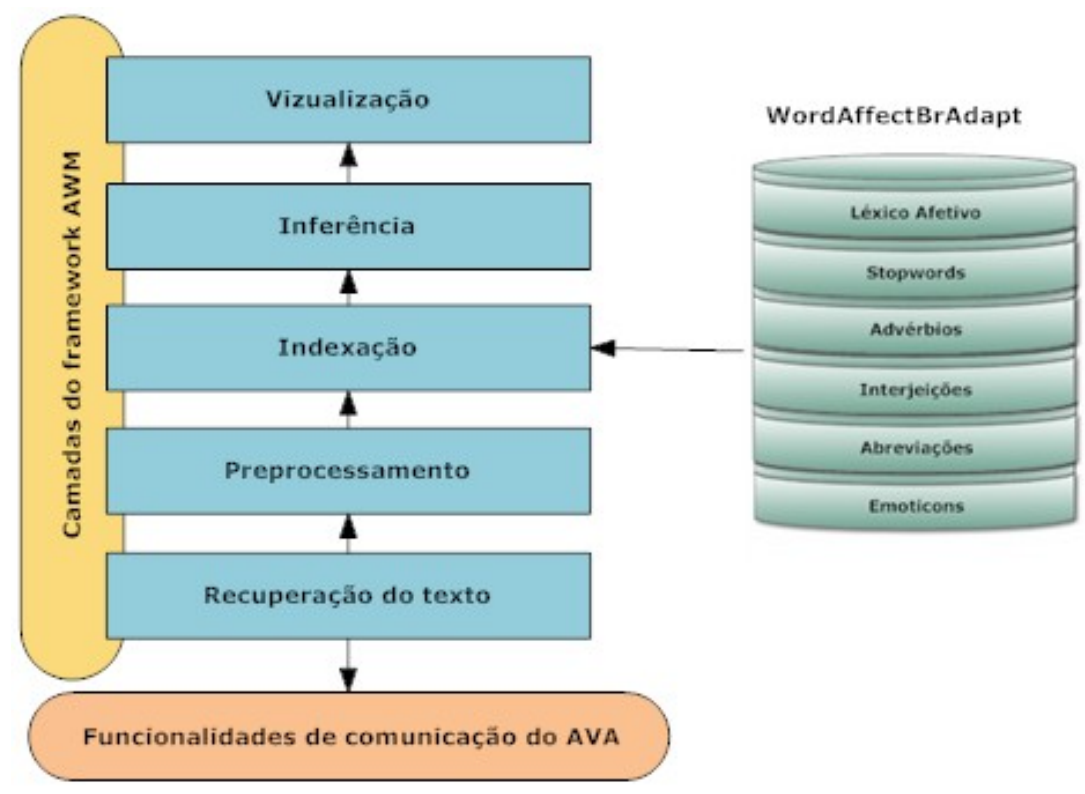

Fig 3. Arquitetura do framework AWM

A função principal do AWM é classificar os estados de ânimo a partir dos termos de significado afetivo encontrados nas frases postadas pelo aluno. Toda mensagem é dividida em frases conforme os demarcadores de texto (pontuação e símbolos de formatação de parágrafo). Cada frase passa pelo processo de tokenização, isto é, as palavras são separadas em lexemas e as não candidatas são eliminadas. A seguir, é verificado a presença do radical da palavra candidata no banco WordAffectBR(adapt). Se presente no banco, a palavra é considerada de caráter afetivo e, então, o quadrante e o subquadrante são identificados; caso contrário, será descartada.

A base WordAffectBR(adapt) é uma extensão do WordAffectBR proposto por Pasqualotti (2008). Atualmente, conta com 5077 palavras, sendo 2183 palavras de conotação afetiva, agrupadas nos quadrantes e subquadrantes correspondentes. As palavras restantes referem-se ao conjunto de advérbios, interjeições, abreviações, stopwords (palavras consideradas irrelevantes, de alta frequência e de baixo valor semântico para o contexto do trabalho, tais como: artigos, preposições, pronomes e alguns verbos e advérbios) e emoticons. 


\section{Abordagem metodológica e resultados encontrados}

Para validar e verificar a acurácia do framework AWM foram analisadas 221 mensagens disponibilizadas por 20 alunos em tópicos de fórum da disciplina Oficinas Virtuais de Aprendizagem ministrada em 2007/1. O AVA ROODA deu suporte às trocas entre os alunos a respeito das temáticas desenvolvidas na disciplina.

A distribuição das mensagens por aluno é mostrada na Tabela 1 . O número total de frases consideradas foi de 1567, do qual foram reconhecidas 2222 palavras de conotação afetiva. A média total de termos afetivos é de 1,42 palavras por frase. Cabe destacar que as interjeições e os emoticons são considerados palavras significativas, e explica o valor aparentemente alto da média encontrado. A quantidade superior de palavras positivas (1419) às de negativas (803) mostra-se de acordo com o esperado. Os alunos tentam manter uma conduta mais positiva na exposição de suas ideias em mensagens de Fórum

Tabela 1: Distribuição do léxico afetivo de 20 alunos

\begin{tabular}{|r|r|r|r|r|r|r|}
\hline \multirow{2}{*}{ Aluno } & \multirow{2}{*}{ Msgs } & \multirow{2}{*}{ Frases } & \multicolumn{4}{|c|}{ Palavras Significativas } \\
\cline { 5 - 7 } & & & frequência & média & Positivas & Negativas \\
\hline 9698 & 16 & 40 & 140 & 3,50 & 87 & 53 \\
\hline 16564 & 7 & 47 & 71 & 1,51 & 44 & 27 \\
\hline 17093 & 37 & 235 & 246 & 1,05 & 131 & 115 \\
\hline 17185 & 6 & 85 & 137 & 1,61 & 100 & 37 \\
\hline 17534 & 10 & 79 & 101 & 1,28 & 74 & 27 \\
\hline 20918 & 6 & 80 & 162 & 2,03 & 107 & 55 \\
\hline 21224 & 32 & 267 & 372 & 1,39 & 219 & 153 \\
\hline 21279 & 14 & 116 & 140 & 1,21 & 100 & 40 \\
\hline 21280 & 6 & 34 & 65 & 1,91 & 42 & 23 \\
\hline 21282 & 11 & 68 & 74 & 1,09 & 42 & 32 \\
\hline 21284 & 8 & 53 & 102 & 1,92 & 71 & 31 \\
\hline 21285 & 12 & 89 & 79 & 0,89 & 51 & 28 \\
\hline 21287 & 1 & 6 & 11 & 1,83 & 9 & 2 \\
\hline 21325 & 8 & 61 & 69 & 1,13 & 43 & 26 \\
\hline 21386 & 4 & 51 & 86 & 1,69 & 57 & 29 \\
\hline 21619 & 21 & 115 & 194 & 1,69 & 120 & 74 \\
\hline 21620 & 2 & 18 & 37 & 2,06 & 24 & 13 \\
\hline 21621 & 1 & 9 & 4 & 0,44 & 4 & 0 \\
\hline 21624 & 12 & 66 & 72 & 1,09 & 50 & 22 \\
\hline 21625 & 7 & 48 & 60 & 1,25 & 44 & 16 \\
\hline Total & 221 & 1567 & 2222 & 1,42 & 1419 & 803 \\
\hline & & & & & & \\
\hline
\end{tabular}

A Figura 4 mostra a frequência dos termos afetivos agrupados por quadrantes que identificam os estados de ânimo. Verifica-se, pela quantidade de mensagens postadas, que os alunos 21224 e 17093 foram os que mais discutiram nos tópicos do fórum. Por isso, não se pode afirmar que o primeiro estava mais satisfeito e o segundo mais desanimado que seus colegas. Mas, que o primeiro utilizou mais palavras de 
conotação positiva que indicam estar satisfeito e o segundo, mais palavras de conotação negativa para desânimo.

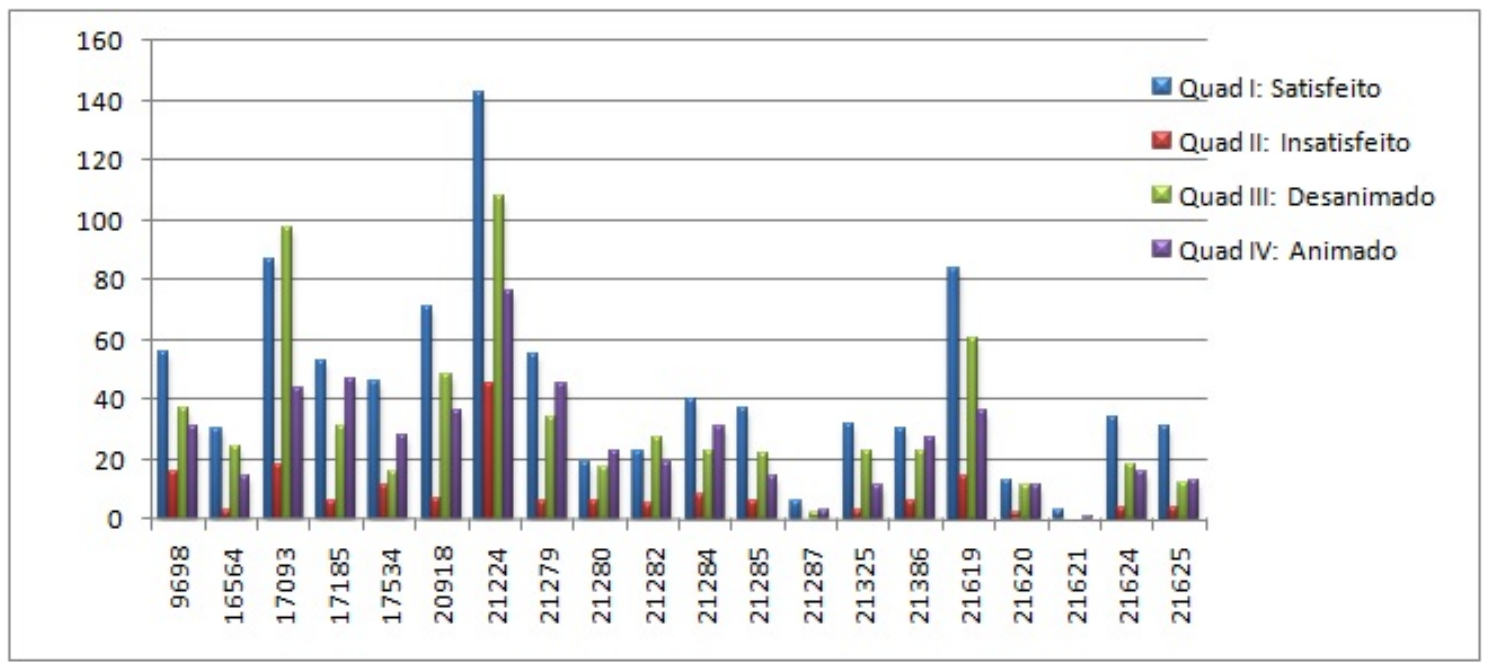

Fig. 4: Distribuição dos termos afetivos nas mensagens do fórum

Destaca-se também, na Figura 4, o resultado apresentado pelo aluno 21282 cujo resultado mostra a tendência para o estado de ânimo desanimado. O aluno 21282 (escolhido neste estudo por apresentar um número médio de mensagens da população analisada) postou 11 mensagens. Percebe-se, na Figura 5, as mudanças de estados de ânimo desse aluno no decorrer do tempo. Embora ele tenha permanecido mais tempo em estado de desânimo (quadrante 3), na última mensagem disponibilizada, o texto inclui conteúdo de satisfação (quadrante 1).

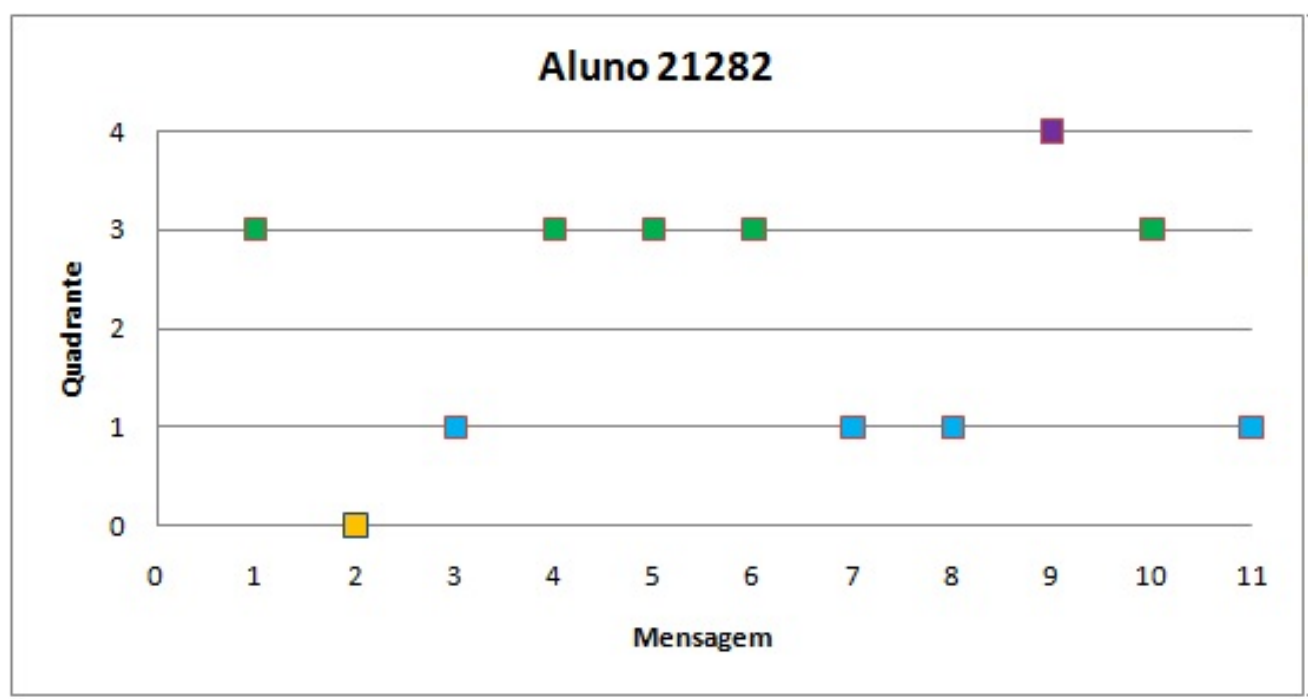

Fig. 5: Variação dos estados de ânimo do aluno 21282 em 11 mensagens

Na Figura 6 observa-se a porcentagem de classificação dos termos afetivos pelo framework AWM: 64\% dos termos afetivos usados pelos alunos remetem a um sentimento positivo (animado ou satisfeito) com as temáticas da disciplina, enquanto que 36\% estavam imbuídos de sentimentos negativos (desanimado ou insatisfeito) . 


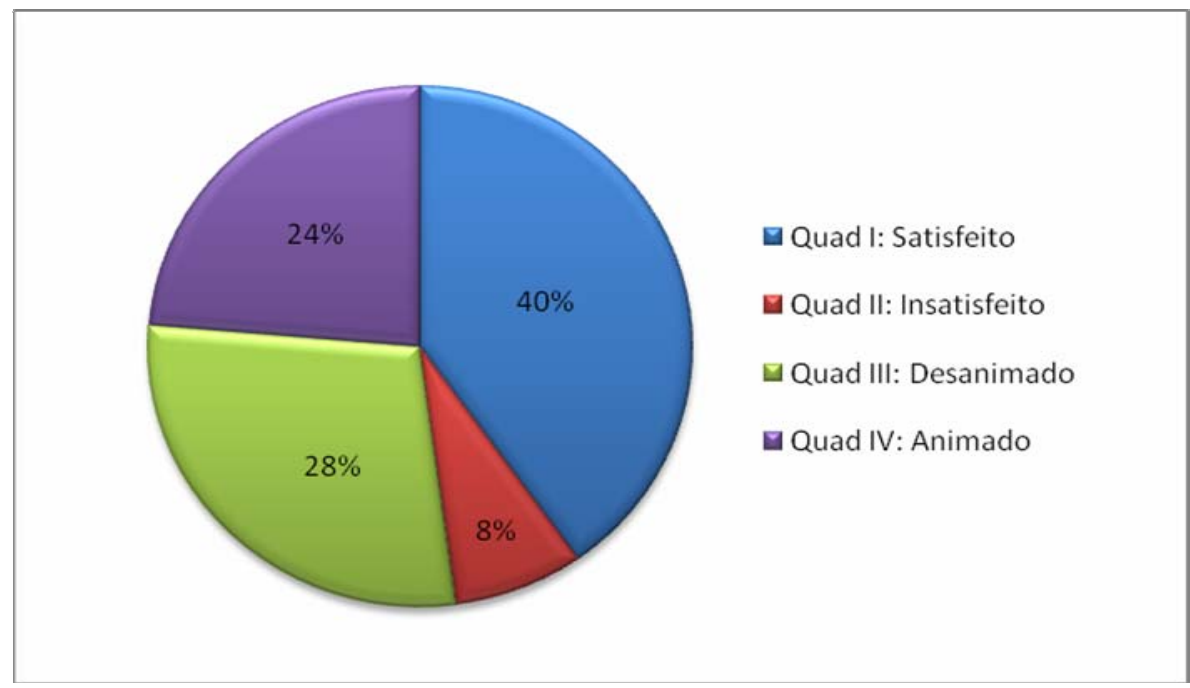

Fig. 5: Porcentagem de classificação dos termos afetivos pelo framework AWM

\section{Considerações finais}

Este trabalho apresenta contribuições na área de reconhecimentos de estados afetivos em textos disponibilizados nas funcionalidades de comunicação síncrona e assíncrona de ambientes virtuais de aprendizagem. O framework AWM se apresenta como um sistema classificador de palavras com conotação afetiva baseado na Roda dos Estados de Afetivos (REA). A REA representa os estados emocionais em um espaço bidimensional determinados pelos eixos da valência (positiva ou negativa) e de autocontrole (alto ou baixo).

Os resultados demonstram a viabilidade do framework, pois se confirmou a porcentagem apresentada na Figura 6 pela análise humana. Entretanto, novos testes, com um corpus de mensagens mais robusto, devem ser realizados para verificar ajustes. Durante os experimentos, alguns termos que não deveriam ser tratados como afetivos, o foram. Isso devido ao processo de radicalização. Um exemplo característico é a conjugação do verbo "estar”. Em qualquer tempo verbal, o resultado da radicalização é "est”. A palavra "estima” também possui o radical "est”. Na indexação das palavras, o framework considerou o verbo "estar" como "estima” distorcendo os resultados finais. Assim, o verbo "estar" passou a pertencer à lista de stopwords para evitar classificação infundada.

O próximo passo é aplicar o framework nas mensagens disponibilizadas pelas funcionalidades do ROODA de comunicação síncrona como Bate-papo e de comunicação assíncrona tais como Diário de Bordo, Lista de Discussão e Contatos.

\section{Referências Bibliográficas}

ALM, C.O.; ROTH, D. \& SPROAT, R. (2005) Emotions from text: machine learning for text-based emotion prediction. In: Proceedings of HLT/EMNLP.

AZEREDO, J. C. (2008). Gramática Houaiss da Língua Portuguesa. São Paulo: Publifolha.

BEHAR, P. A. (2009) Modelos Pedagógicos em Educação a Distância. Porto Alegre: Artmed. 
DAMÁSIO, A. (1996) O Erro de Descartes: emoção, razão e o cérebro humano. Tradução: Dora Vicente e Georgina Segurado. São Paulo: Cia das Letras, 1996.

EKMAN, P. (1999) Basic Emotions In: T. Dalgleish and T. Power (Eds.) The Handbook of Cognition and Emotion. p. 45-60. Sussex, U.K.: John Wiley \& Sons, Ltd.

GALATI, D.; SINI, B.; TINTI, C.; \& TESTA, S. (2008) The lexicon of emotion in the neo-Latin languages. In: Social Science Information, Vol. 47, No. 2: 205-220.

GARCIA, O. M. (1982). Comunicação em prosa moderna: aprenda a escrever, aprendendo a pensar. Rio de Janeiro: FGV.

GILL, A.J, FRENCH, R.M, GERGLE,D., OBERLANDER, J. (2008). The Language of Emotion in Short Blog Texts. In: CSCW'08, November 8-12, 2008, San Diego, California, USA.

GRANDJEAN D.; BANZIGER T. \& SCHERER K. R. (2006) Intonation as an interface between language and affect. In: Progress in Brain Research 156:235-268.

JAQUES, P. A.; LEHMANN, M.; \& PESTY, S. (2009) Evaluating the Affective Tactics of an Emotional Pedagogical Agent. In: ACM Symposium on Applied Computing - Human Computer Interaction Track, 2009, Hawai. New York : ACM, 2009. v. 1. p. 104-109.

KAPOOR, A. \& PICARD, R. E. (2005) Multimodal Affect Recognition in Learning Environments, In: ACM MM’05, November 6-11, Singapore. 2005.

KAPUR, A., KAPUR, A., VIRJI-BABUL, N., TZANETAKIS, G. \&. DRIESSEN, P.F. (2005) Gesture-Based Affective Computing on Motion Capture Data. In: Proceedings of the International Conference on Affective Computing and Intelligent Interaction (ACII), Beijing, China, October, 2005.

LONGHI, M. T.; BEHAR, P. A. \& BERCHT, M. (2009a) “AnimA-K: recognizing student's mood during the learning process”. In: WCCE 2009 - 9th IFIP World Conference on Computers in Education, Bento Gonçalves, RS, Brazil. July 2731.

LONGHI, M. T.; BEHAR, P. A.; BERCHT, M. e SIMONATO, G. (2009b) Investigando a subjetividade afetiva na comunicação assíncrona de ambientes virtuais de aprendizagem. In: Anais do SBIE2009 - XX Simpósio Brasileiro de Informática na Educação, Florianópolis, SC. Novembro.

MARTINS, N. S. (2008). Introdução à estilística. São Paulo: EDUSP.

PASQUALOTTI, P. R. (2008). Reconhecimento de expressões de emoções na interação mediada por computador. Computação Aplicada. UNISINOS, Dissertação de Mestrado. São Leopoldo.

PIAGET, J. Inteligencia y afectividad. Buenos Aires: Aique, 2005.

PIAGET, J. (1973). Estudos Sociológicos. Rio de Janeiro: Forense.

SCHERER, K. R.(2005) What are emotions? And how can they be measured? In: Social Science Information 44 (4), 695-729.

SCHERER, K. R. (1995) How Emotion is Expressed in Speech and Singing. In: ICPhS 95, Vol. 3, p. 90.

TRAN, V. (2004) The influence of emotions on decision-making processes in management teams. Faculte De Psychologie et des Sciences de l'Education. Université de Genève. Thèse No 323.

TRASK, R. L. (2008). Dicionário de Linguagem e Linguísitica. (Trad. Ilari, R.). São Paulo: Contexto. 